\title{
A review of Parydra (Diptera: Ephydridae) from Brazil
}

\author{
Wayne N. Mathis ${ }^{1} \&$ Luciane Marinoni $^{2}$
}

\author{
${ }^{1}$ Department of Entomology, NHB 169, PO Box 37012, Smithsonian Institution, Washington, D.C., 20013-7012, USA. \\ E-mail: mathisw@si.edu \\ ${ }^{2}$ Departamento de Zoologia, Universidade Federal do Paraná. Caixa Postal 19020, 81531-980 Curitiba, PR, Brazil. \\ E-mail: Imarinoni@ufpr.br
}

\begin{abstract}
Species of the shore-fly Parydra Stenhammar, 1844 from Brazil are reviewed with an emphasis on the fauna from southern Brazil, where one new species, Parydra arcuata sp. nov. - state of Paraná, municipality of Castro $(8 \mathrm{~km} \mathrm{~N}$, $\left.24^{\circ} 45.3^{\prime} \mathrm{S}, 4^{\circ} 58.9^{\prime} \mathrm{W}\right)$-, has been discovered and is herein described. To facilitate identification of species, we have included a diagnosis of the genus. We have also provided illustrations of structures of the male terminalia for all included species.
\end{abstract}

KEY WORDS. Neotropical Region; shore flies; taxonomy.

This review of Parydra Stenhammar, 1844 was prompted by recent field work in southern Brazil that is part of an overall survey of the shore flies of this biologically diverse country. An objective of the field work in 2009-2010 was the shore-fly fauna from the state of Paraná and to a lesser degree from Santa Catarina and São Paulo and resulted in numerous specimens of Parydra. We soon discovered that three species were represented in this fauna and that one is undescribed. The purpose of this paper is to describe this new species within the context of a faunistic review of the genus from Brazil.

In the Neotropical Region, the shore-fly genus Parydra is biologically diverse with 16 species (Clausen 1985, Mathis \& ZATWARNICKI 1995). Many of these species, however, represent southern extensions of otherwise Nearctic species, and only eight species - Parydra nigripes (Cresson, 1918); P. aureola Cresson, 1931; P. cishumilis Clausen, 1985; P. humilis Williston, 1897; P. lynetteae Clausen \& Cook, 1971; P. ochropus (Thomson, 1868); P. spiculosa Clausen, 1985; P. truncatula Clausen, 1985 have wholly or mostly Neotropical distributions.

In general, temperate and boreal zones in the Northern Hemisphere have far greater diversity at the species level in Parydra than has the Neotropics. For example, 34 species occur in the Nearctic Region compared with eight in the Neotropical Region. Thus, discovery of a relatively large bodied, new species in southern Brazil was somewhat unanticipated, especially as the genus had relatively recently been revised (CLAUSEN 1985).

Worldwide, Parydra is one of four genera included in Parydrini Wirth \& Stone, 1956 (Ephydrinae Zetterstedt), which was characterized relatively recently in the nomenclatural history of shore flies. The Nearctic genera and species of Parydrini were thoroughly revised (CLAusen \& Cook 1971), including a lengthy tribal diagnosis. The other three genera in Parydrini are Callinapaea Sturtevant \& Wheeler, 1954 (Nearctic),
Eutaenionotum Oldenberg, 1923 (Holarctic), and Rhinonapaea Wirth, 1965 (Nearctic). These three genera are only known from the Northern Hemisphere where they primarily occur in the boreal zone. Only Parydra and its three subgenera (Chaetoapnaea Hendel, 1930; Paranapaea Hendel, 1930; Parydra) are relatively more widespread, and only the subgenera Chaetoapnaea and Parydra include species that are found in tropical zones (MathIs \& ZATWARNICKI 1995).

Both larvae and adults of Parydra feed on algae and are found along the muddy shores of lentic and lotic aquatic systems (Bischof \& Deonier 1985, Foote 1995).

\section{MATERIAL AND METHODS}

The descriptive terminology, with the exceptions noted in Mathis (1986) and Mathis \& Zatwarnicki (1990a), follows that published in the 'Manual of Nearctic Diptera' (McAlPine 1981). Because specimens of Parydrini are generally moderately small, usually less than $4.0 \mathrm{~mm}$ in length, study and illustration of the male terminalia required use of a compound microscope. We have followed the terminology for most structures of the male terminalia that other workers in Ephydridae have used (see references in Mathis 1986, Mathis \& Zatwarnicki 1990a, b), such as surstylus. ZatWARNICKI (1996) suggested that the preand postsurstylus correspond with the pre- and postgonostylus and that the subepandrial plate is the same as the medandrium. The terminology for structures of the male terminalia is provided in the legends.

Dissections of male and female genitalia and descriptions were performed using the method of CLAusen \& Cook (1971) and GRIMALDI (1987). Microforceps were used to remove abdomens, which were macerated in a potassium hydroxide solution. Cleared genitalia were rinsed in a dilute solution of acetic 
acid and then transferred to glycerin for observation and illustration. If necessary for proper orientation, the specimen was transferred from glycerin to glycerin jelly. The glycerin jelly was heated, and the specimen appropriately oriented. After cooling, the embedded specimen in glycerin jelly became immobilized. The abdomen was placed in a plastic microvial filled with glycerin and attached to the pin supporting the remainder of the insect from which it was removed.

The new species description is composite and not based solely on the holotype. Two head and two venational ratios used in the descriptions are based on three specimens (largest, smallest, and one other): eye ratio: maximum width/maximum height; gena-to-eye ratio: genal height (immediately below maximum eye height)/eye height; costal vein ratio: the straight line distance between the apices of $\mathrm{R}_{2+3}$ and $\mathrm{R}_{4+5}$ /distance between the apices of $\mathrm{R}_{1}$ and $\mathrm{R}_{2+3}$; $\mathrm{M}$ vein ratio: the straight line distance along vein $\mathrm{M}$ between crossveins $\mathrm{dm}-\mathrm{cu}$ and $\mathrm{r}-\mathrm{m} /$ distance apicad of $\mathrm{dm}-\mathrm{cu}$.

Specimens for this study are in the American Museum of Natural History, New York, New York (AMNH); Academy of Natural Sciences of Philadelphia, Philadelphia, Pennsylvania (ANSP); Universidade Federal do Paraná, Coleção Entomológica Padre Jesus Santiago Moure, Departamento de Zoologia, Curitiba, Paraná (DZUP); Museu Nacional, Rio de Janeiro, Rio de Janeiro (MNRJ); Museu de Zoologia da Universidade de São Paulo, São Paulo (MZUSP); Naturhistoriska Riksmuseet, Stockholm (NRS); and the National Museum of Natural History, Smithsonian Institution, Washington, D.C. (USNM).

\section{TAXONOMY}

\section{Parydrini Wirth \& Stone, 1930}

Napaeini Cresson, 1930: 100. Type genus: Napaea RobineauDesvoidy, 1830, preoccupied, Hübner, 1819. Unavailable, based on a junior homonym.

Parydrini Wirth \& Stone, 1956: 464. Type genus: Parydra Stenhammar, 1844; Mathis \& Zatwarnicki 1995: 214-229 [world catalog].

\section{Parydra Stenhammar, 1844}

Napaea Robineau-Desvoidy, 1830: 799. Type species: Napaea stagnicola Robineau-Desvoidy, 1830, subsequent designation, Coquillett, 1910: 573. Preoccupied, Hübner, 1819.

Parydra Stenhammar, 1844: 144 [as "Sectio 3" of Ephydra]. Type species: Ephydra aquila Fallén, 1813, subsequent designation, Coquillett, 1910: 585; Wirth, 1965: 749-750 [Nearctic catalog]; 1968: 21-22 [Neotropical catalog]; Clausen \& Cook, 1971: 20-100 [revision of Nearctic species]; Clausen, 1985: 361-384 [revision of Neotropical species]; Mathis \& Zatwarnicki, 1995: 216-229 [world catalog].

Diagnosis. Parydra is distinguished from other genera of Parydrini by the following combination of characters: Small to large shore flies, body length $1.85-5.50 \mathrm{~mm}$; usually densely golden, coppery, and grayish microtomentose. Head: frontoorbital and ocular setae present, lateroclinate, frequently not well developed. Arista well developed, macropubescent. Face in lateral view straight to concave or convex, usually densely microtomentose, coppery, golden to silvery white; anterior oral margin in lateral view extended beyond antennal bases; facial carina near antennal bases, not extended beyond level of oral margin; facial series of setae with only dorsal seta or 2 developed, inserted near parafacial; oral margin lacking setae. Clypeus exposed and generally visible. Thorax: wing with costa long, extended to vein $\mathrm{M}$, making costal section II over 3X length of section III; crossvein r-m located distinctly beyond level of junction of vein $\mathrm{R}_{1}$ with costa. Abdomen: heavily sclerotized; black with gray to coppery microtomentum. Male terminalia: Epandrium usually greatly narrowed dorsally above cerci; surstylus fused with ventral margin of epandrium; aedeagus and phallapodeme sometimes fused; gonite variously shaped but usually elongate and often narrowly rounded or pointed apically. Female ventral receptacle variously shaped, operculum often large, thimble-like with small extended process but also with operculum small and with a relatively larger extended process.

\section{Chaetoapnaea (Chaetoapnaea) Hendel, 1930}

Chaetoapnaea Hendel, 1930: 150. Type species: Ephydra pusilla Meigen, 1830, original designation.

Diagnosis. This subgenus is distinguished from Parydra sensu stricto by the following combination of characters: Head: face in lateral view straight to concave. Thorax: scutellum usually lacking tubercles or an apical process. Abdomen: male terminalia with aedeagus usually fused to phallapodeme, gonites usually pointed apically, subepandrial plate or arch usually absent.

\section{Parydra (Chaetoapnaea) nigripes (Cresson, 1918)} Figs 1-6

Napaea nigripes Cresson, 1918: 64 [Costa Rica. Cartago: Cartago $\left(9^{\circ} 51.4^{\prime} \mathrm{N}, 85^{\circ} 55.3^{\prime} \mathrm{W}\right.$; sweeping over mud); HT male, ANSP (6138)].

Parydra nigripes; Wirth, 1968: 22 [generic combination; Neotropical catalog]; Clausen, 1985: 378-382 [revision]; Lizarralde de Grosso, 1989: 51 [list, Argentina]; Mathis \& Zatwarnicki, 1995: 218-219 [world catalog].

Diagnosis. This species is distinguished from congeners by the following combination of characters: small to mediumsized shore flies, body length 2.55-3.65 mm. Head: frons with subshiny to shiny mesofrons and fronto-orbits, parafrons dull, microtomentose. Scape and pedicel blackish brown; basal flagellomere mostly blackish brown, sometimes partially yellowish basoventrally. Face in lateral view sloping anteriorly, very shallowly curved, sparsely microtomentose, subshiny, duller than mesofrons, blackish brown; clypeus like face. Thorax: wing ra- 

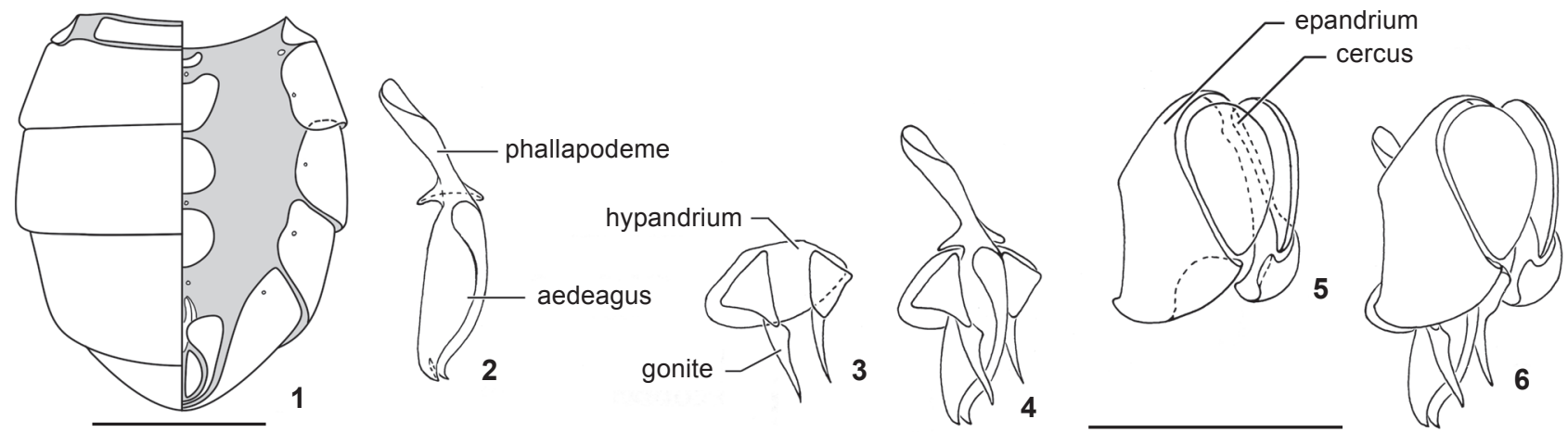

Figures 1-6. Parydra nigripes: (1) abdomen of male, dorsal and ventral views; (2) aedeagus and phallapodeme, latero-oblique view; (3) gonite and hypandrium, latero-oblique view; (4) gonite, hypandrium, phallapodeme, latero-oblique view; (5) epandrium and cercus, latero-oblique view; (6) male terminalia, latero-oblique view. Scale bars: $1=0.5 \mathrm{~mm} ; 2-6=0.25 \mathrm{~mm}$.

tio: 0.39-0.40; costal vein ratio: 0.60-0.71. Femora and tibiae black; tarsi blackish yellow, more yellowish ventrally. Abdomen: male terminalia (Figs 1-6): aedeagus and phallapodeme fused (Figs 2 and 4); aedeagus long, length twice width, with apex slightly recurved or hooked; phallapodeme long, slender; gonite long and slender, narrowly pointed apically.

Distribution. Neotropical: Argentina, Colombia, Costa Rica (Cartago), Ecuador, Guatemala, Honduras, Mexico (Chihuahua, Durango).

Remarks. Although no specimens of this species are known from Brazil, we have included it in this review as it has been recorded from adjacent countries (MATHIS \& ZatwARNICKI 1995) and may eventually be found in Brazil.

\section{Parydra (Parydra) Stenhammar, 1844}

Napaea Robineau-Desvoidy, 1830: 799. Type species: Napaea stagnicola Robineau-Desvoidy, 1830, subsequent designation, Coquillett 1910: 573. Preoccupied, Hübner, 1819; Haliday, 1855: 57 [synonymy].

Parydra Stenhammar, 1844: 144 (as "Sectio 3" of Ephydra). Type species: Ephydra aquila Fallén, 1813, subsequent designation, Coquillett, 1910: 585; Mathis \& Zatwarnicki, 1995: 221-229 [world catalog].

Falosoma Lioy, 1864: 1102 (neuter). Type species: Ephydra aquila Fallén, 1813, subsequent designation, Coquillett, 1910: 544; Coquillett, 1910: 544 [synonymy].

Hygrophila Lioy, 1864: 1102. Type species: Ephydra fascipennis [sic] Macquart, 1835, monotypy; Coquillett 1910: 554 [synonymy].

Diagnosis. This subgenus is distinguished from Chaetoapnaea by the following combination of characters: Head: Face in lateral view convex. Thorax: scutellum usually with tubercles and/or an apical process. Abdomen: male terminalia: Aedeagus not fused to phallapodeme; gonites rounded apically, subepandrial plate or arch usually present.

\section{Key to Species of Parydra from Brazil}

1. Hindfemur of male distinctly arched (Fig. 11) P. arcuata sp. nov.

1 '. Hindfemur of male essentially straight 2

2. Keel of phallapodeme narrow, clavate (Fig. 19); gonite narrow, slightly tapered toward apex, apex moderately narrowly rounded (Fig. 20) P. humilis Williston

2 '. Keel of phallapodeme subglobose (Fig. 25); gonite moderately narrow, digitiform, apex bluntly rounded with apical process (Fig. 26) P. ochropus (Thomson)

\section{Parydra (Parydra) arcuata, sp. nov.} Figs 7-14

Diagnosis. This species is distinguished from congeners by the following combination of characters: Medium-sized shore flies, body length 3.10-3.40 mm. Head (Figs 7-9): Frons evenly microtomentose, golden brown; 3 fronto-orbital setae evident but all shorter than ocellar seta, middle seta smallest, all obliquely oriented. Antenna brownish orange to brown; arista elongate, bearing numerous short, dorsal rays, longest slightly less than half height of basal flagellomere. Face in lateral view nearly vertical, only slightly sloping; mostly silvery microtomentose, with some bluish or bronze metallic luster dorsally; antennal grooves as semi-triangular, very shallow depressions at about midheight laterally. Eye ratio 1.00-1.10. Gena high, about half eye height, gena to eye ratio $0.40-0.50$. Thorax: Mesonotum mostly brown, microtomentose, but with some faint, grayish vittae; scutellum trapezoidal, truncate apically, only apical setae well developed, lateral scutellar setae less than half length of apical pair. Wing (Fig. 10) generally lightly infuscate with darker clouds over crossveins r-m and dm-cu; costal section II about equal to section III; costal vein ratio 0.89-0.97; M vein ratio 0.81-0.84. Legs yellowish orange to brownish orange; tarsomeres becoming progressively darker toward apex; hindfemur of male (Fig. 11) conspicuously arched, that of female slightly arched; hindtibia of 


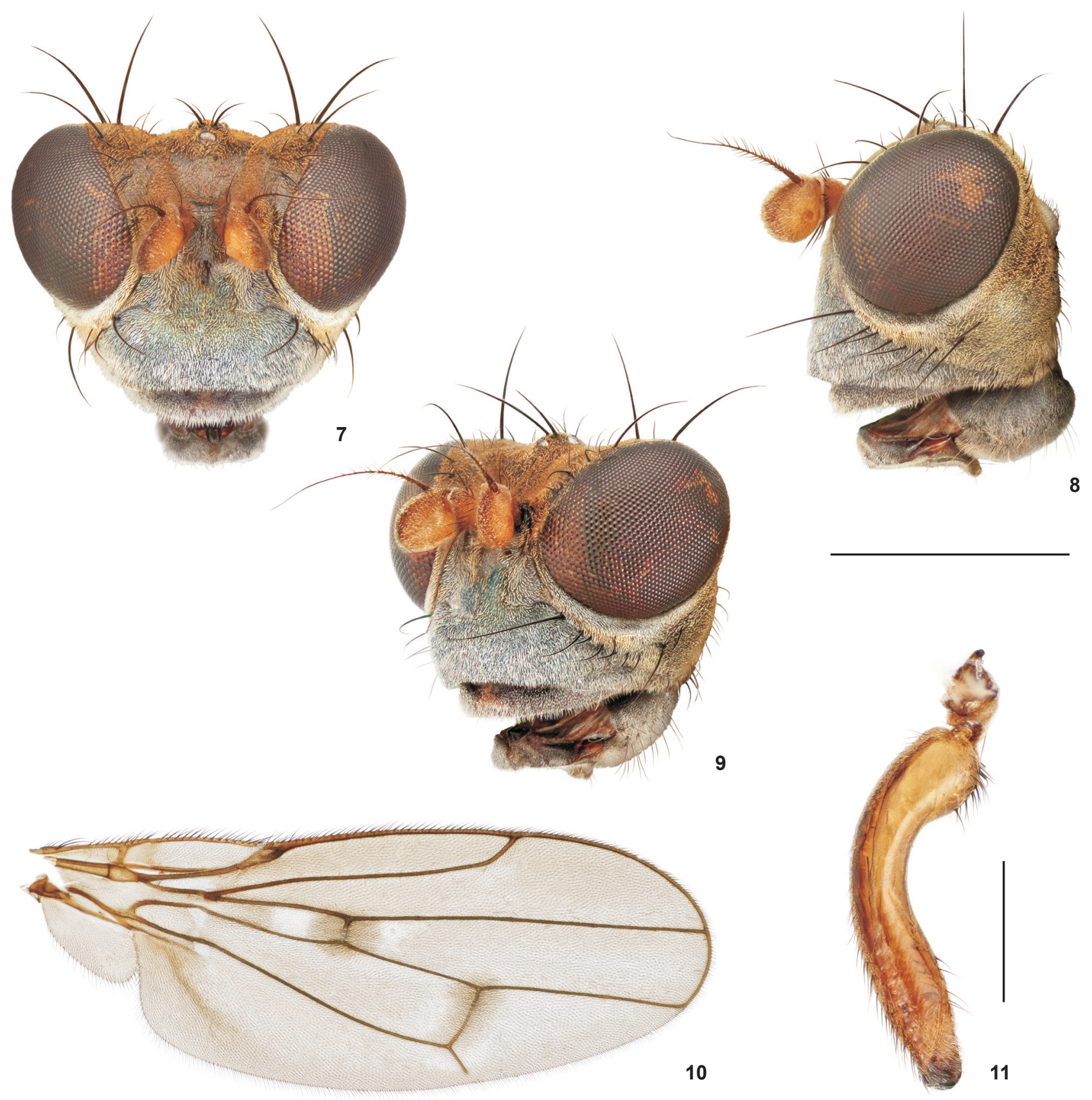

Figures 7-11. Parydra arcuata sp. nov.: (7) head, anterior view; (8) same, lateral view; (9) same, oblique view; (10) wing, dorsal view; (11) hindfemora, posterior view. Scale bars: $0.5 \mathrm{~mm}$.

male angularly arched. Abdomen: Tergites heavily sclerotized and divided into a dorsal tergite and 2 lateral sclerites with a membranous longitudinal crease dividing the dorsal portion from 2 lateral portions. Male terminalia (Figs 12-15): Epandrium in posterior view (Fig. 12) as an inverted U, arms slightly wider at midheight, narrow, almost parallel sided ventrally, in lateral view (Fig. 13) more or less as a parallelogram, pointed dorsally, ventral margin rounded, bearing numerous setulae ventrally; cercus in posterior view broadly lunate to reniform, dorsal and ventral margins narrowly rounded, in lateral view semi-hemispherical; 

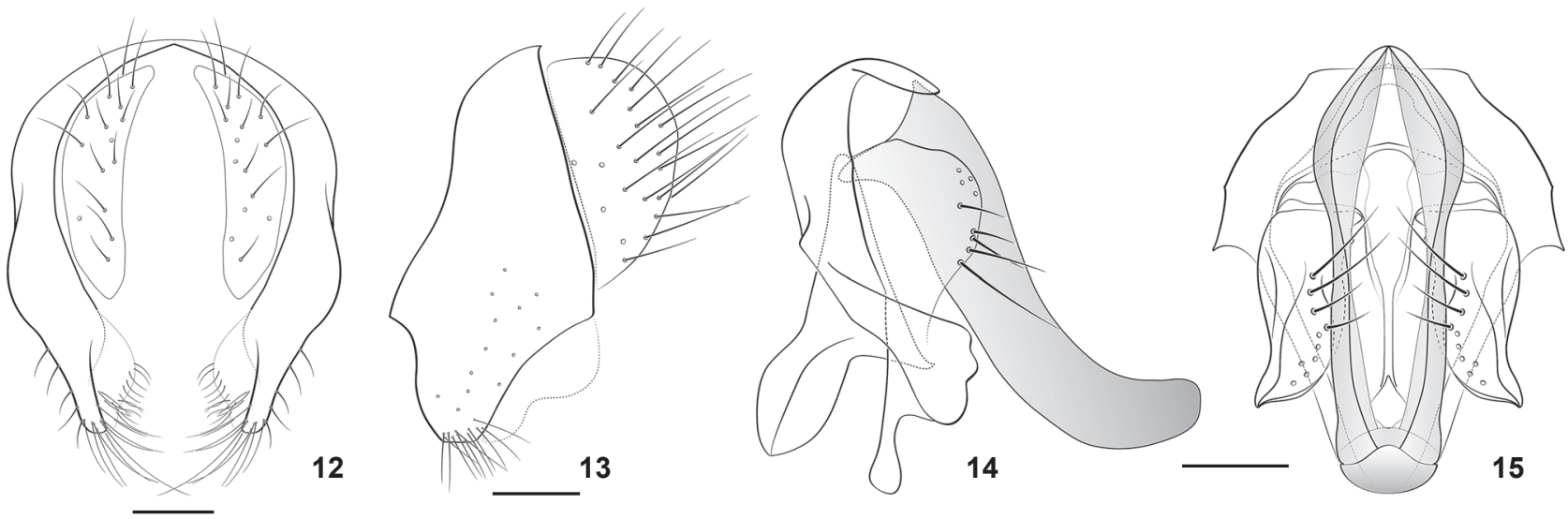

Figures 12-15. Parydra arcuata sp. nov. (12) epandrium and cercus, posterior view; (13) epandrium and cercus, lateral view; (14) aedeagus, phallapodeme, gonite, lateral view; (15) aedeagus, gonite, and hypandrium, ventral view. Scale bars: $0.1 \mathrm{~mm}$.

aedeagus in lateral view (Fig. 14) sinuous, very gradually tapered, bluntly rounded apically, in ventral view digitiform (Fig. 15), widest subapically, apex narrowly pointed; phallapodeme in lateral view (Fig. 14) with long, extended, leaf-like keel; gonite in lateral view with subapical lateral projection, projection apically shallowly trilobed, apically with clavate, narrow projection, in ventral view (Fig. 15) with apex pointed, oriented lateroventrally; hypandrium in ventral view (Fig. 15) broadly and shallowly Ushaped, arms robustly developed.

Type material. The holotype male is labeled "BRAZIL. Paraná: Castro ( $8 \mathrm{~km} \mathrm{~N}$; 2445.3'S, 4958.9'W; $1010 \mathrm{~m}$ ), 25-26 Dec 2009, D. \& W. N. Mathis/HOLOTYPE ơ Parydra arcuata Mathis and Marinoni, DZUP [red]." The holotype is double mounted (minuten in a block of plastic), is in excellent condition, and is deposited in DZUP. Thirteen paratypes (7 males, 6 females; DZUP, USNM) bear the same label data as the holotype. Other paratypes are as follows: Paraná: Curitiba, Universidade Federal do Paraná, Reserva Biológica Mata Viva $\left(25^{\circ}\right.$ 26.9'S, 49 14'W, 915 m), 13 Feb-12 Apr 2010, D. and W.N. Mathis leg. (2 males; DZUP, USNM).

Specimens examined from Brazil. São Paulo: São Paulo

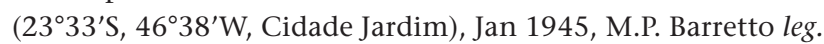
( 2 males, 1 female, MZUSP).

Distribution. Neotropical: Brazil (Paraná, São Paulo).

Etymology. The species epithet, arcuata, is of Latin derivation, meaning "bent like a bow," and has reference to the arched hindfemur of males.

\section{Parydra (Parydra) humilis Williston, 1897}

\section{Figs 16-23}

Parydra humilis Williston, 1897: 7 [Brazil, Rio de Janeiro: Rio de Janeiro $\left(22^{\circ} 54.2^{\prime} \mathrm{S}, 43^{\circ} 12.6^{\prime} \mathrm{W}\right)$; NT male (designated by Clausen, 1985: 369), AMNH]; Thaxter, 1917: 693-695 [parasite: Stigmatomyces lingulatus Thaxter (Laboulbeniaceae)];
Wirth, 1968: 22 [Neotropical catalog]; Clausen, 1985: 368372 [revision].

Napaea humilis; Cresson, 1918: 64 [generic combination]. Parydra humeralis; Cresson, 1931: 104 [misspelling].

Parydra (Parydra) humilis; Clausen \& Cook, 1971: 46-48 [revision of Nearctic species]; Clausen, 1985: 368-372 [revision of Neotropical species, figures of male terminalia]; Lizarralde de Grosso, 1989: 51 [list, Argentina]; Mathis \& Zatwarnicki, 1995: 225 [world catalog].

Diagnosis. This species is distinguished from congeners by the following combination of characters: Medium-sized to large shore flies, body length 3.20-3.95 mm. Head: fronto-orbital setae relatively long; face in lateral view convex; clypeus golden to grayish gold; maxillary palpus usually yellowish. Thorax: scutellum lacking apical process or papilla; apical setae lacking basal tubercles. Wing relatively clear, lacking conspicuous spots or darkened areas; wing ratio: 0.40-0.46; costal vein ratio: 0.60-0.70. Legs, except black base of coxae, reddish to yellowish red, apical tarsomeres brown; hindtibia with yellow posteroapical comb, paler than rest of tibia; gonites flattened, with rounded, slightly curved apices. Abdomen: Male terminalia (Figs 16-23): aedeagus not fused to phallapodeme (Figs 17 and 21); phallapodeme (Figs 19, 21, and 23) elongate, comparatively narrow, especially keel, which becomes slightly wider apically; subepandrial arch narrowly triangular; gonite in lateral view (Figs 20 and 21) flattened, straight to very slightly curved, apex narrowly rounded to rounded, bearing 3-4 setulae ventrally.

Specimens examined from BraziL, Espírito Santo: Baixo

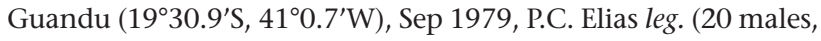
24 females, MZUSP). Paraná: Antonina $\left(25^{\circ} 28.4^{\prime} \mathrm{S}, 48^{\circ} 40.9^{\prime} \mathrm{W}\right.$, beach/mangal), 9 Apr-14 Nov 2010, D. and W.N. Mathis leg. (13 males, 1 female; DZUP, USNM); Bocaiúva do Sul $\left(25^{\circ} 16.6^{\prime}\right.$ ', $\left.48^{\circ} 58.5^{\prime} \mathrm{W}, 770 \mathrm{~m}\right), 16 \mathrm{Feb} 2010$, D. and W.N. Mathis leg. (10 males; DZUP, USNM); Castro (Parque Lacustre, $24^{\circ} 47.4^{\prime} \mathrm{S}, 50^{\circ} 0.3^{\prime} \mathrm{W}$, 

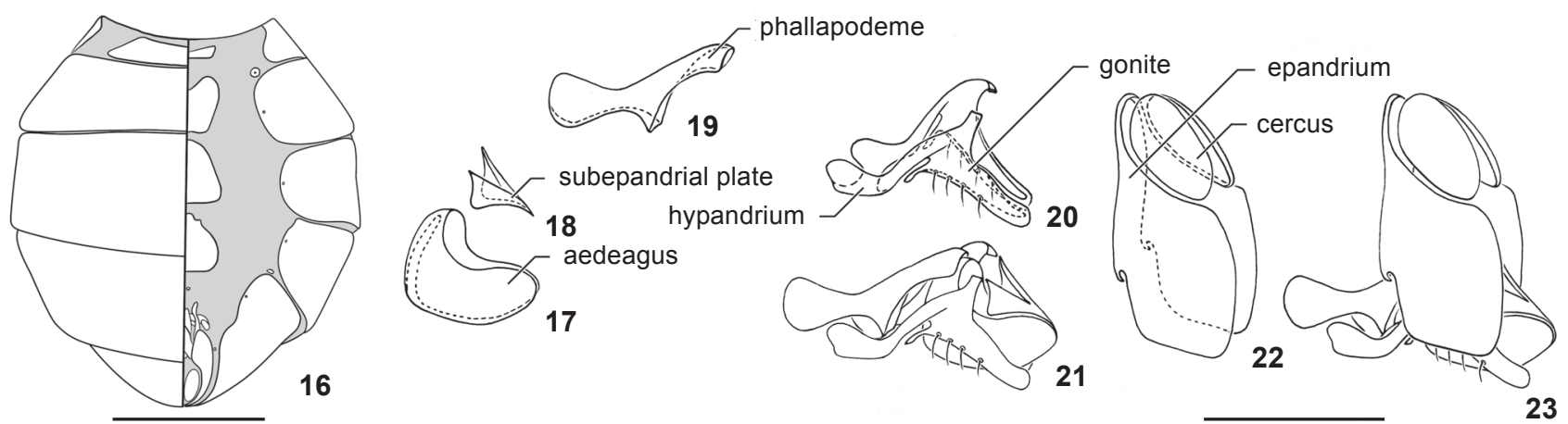

Figures 16-23. Parydra humilis: (16) abdomen of male, dorsal and ventral views; (17) aedeagus, latero-oblique view; (18) subepandrial plate, latero-oblique view; (19) phallapodeme, latero-oblique view; (20) gonite and hypandrium, latero-oblique view; (21) aedeagus, gonite, hypandrium, phallapodeme, latero-oblique view; (22) epandrium and cercus, latero-oblique view; (23) male terminalia, laterooblique view. Scale bars: $16=0.5 \mathrm{~mm}, 17-23=0.25 \mathrm{~mm}$.

990 m), 31 Dec-1 Jan 2009, 2010, D. and W.N. Mathis leg. (5 males, 1 female; DZUP, USNM); Castro ( 8 km N; $24^{\circ} 45.3^{\prime} \mathrm{S}, 49^{\circ} 58.9^{\prime} \mathrm{W}$, 1010 m), 24 Dec-1 Jan 2009, 2010, D. and W.N. Mathis leg. (8 males, 1 female; DZUP, USNM); Curitiba, Universidade Federal do Paraná, Reserva Biológica $\left(25^{\circ} 26.9^{\prime}\right.$ S, $49^{\circ} 14^{\prime}$ W, 915 m), 15 Dec6 Feb 2009, 2010, D. and W.N. Mathis leg. (43 males, 4 females, DZUP, USNM); Parque Iguaçu ( $\left.25^{\circ} 33.4^{\prime} \mathrm{S}, 49^{\circ} 13.6^{\prime} \mathrm{W}, 880 \mathrm{~m}\right), 22$ Jan-12 Apr 2010, D. and W.N. Mathis leg. (16 males, DZUP, USNM); Santo Antônio, Fazenda Dora $\left(24^{\circ} 35^{\prime} S, 50^{\circ} 23^{\prime} \mathrm{W}\right)$, Jun 1965 , N. Papavero leg. (1 female, MZUSP). Rio de Janeiro: Jacarepaguá, Barra da Tijuca $\left(22^{\circ} 58.7^{\prime} \mathrm{S}, 43^{\circ} 23.7^{\prime} \mathrm{W}\right)$, Sep 1934, H. Souza Lopes leg. (1

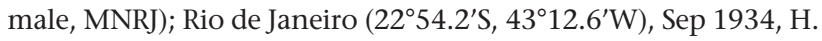
Souza Lopes leg. (2 males, 4 females, MNRJ). Rio Grande do Sul: Torres $\left(29^{\circ} 21^{\prime} \mathrm{S}, 49^{\circ} 44^{\prime} \mathrm{W}\right)$, Jun 1965 , N. Papavero leg. (1 female,

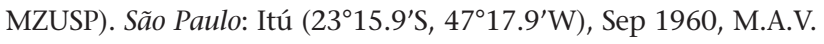
D'Andretta leg. (2 males, 1 female, MZUSP).

Distribution. Nearctic: United States (California). Neotropical: Brazil (Espirito Santo, Paraná, Rio de Janeiro, Rio Grande do Sul, São Paulo), Costa Rica, Honduras, Mexico (Chiapas, Sinaloa, Tabasco, Veracruz-Llave), Panamá, Peru, West Indies (Cuba, Dominica, Dominican Republic, Jamaica, Virgin Islands).

\section{Parydra (Parydra) ochropus (Thomson, 1868)} Figs 24-29

Ephydra ochropus Thomson, 1868: 592 [Uruguay. Montevideo $\left(34^{\circ} 54.4^{\prime} \mathrm{S}, 56^{\circ} 09.9^{\prime} \mathrm{W}\right)$; HT female, NRS].

Napaea ochropus; Hendel, 1930: 147 [generic combination].

Parydra ochropus; Wirth, 1968: 22 [generic combination; Neotropical catalog]; Clausen, 1985: 372-374 [revision]; Lizarralde de Grosso, 1989: 50-51 [list, Argentina]; Mathis \& Zatwarnicki, 1995: 226-227 [world catalog].

Napaea flavipes Hendel, 1930: 147 [Argentina. San José; LT male (designated by Clausen 1985: 373, NMW]; Clausen 1985: 372 [synonymy].

Parydra flavipes; Wirth 1968: 22 [generic combination].
Diagnosis. This species is distinguished from congeners by the following combination of characters: Medium-sized shore flies, body length $3.10-3.70 \mathrm{~mm}$. Head: Fronto-orbital setae relatively long; face in lateral view convex; clypeus golden to grayish gold; maxillary palpus yellow to reddish yellow. Thorax: Scutellum lacking apical process or papilla but apical setae arising from tubercles. Wing relatively clear, lacking conspicuous spots or darkened areas; wing ratio: 0.42-0.43; costal vein ratio: 0.40-0.44. Legs, except black base of coxae, reddish to yellowish red, apical tarsomeres brown; hindtibia with yellow posteroapical comb, much paler than rest of tibia; gonites flattened, with rounded, slightly curved apices. Abdomen: Male terminalia (Figs 24-29): Aedeagus not fused to phallapodeme (Fig. 25); phallapodeme in lateral view (Fig. 24) with elongate, thickened keel; subepandrial arch (Fig. 26) present; gonite in lateral view straight, becoming slightly wider toward apex, generally thickened, apex truncate, sometimes with a very short, posterodorsal projection, bearing 4-5 setulae ventrally; hypandrium (Figs 26 and 27) wider than long in ventral view, anterior margin shallowly concave.

Specimens examined from BraziL, Santa Catarina: Nova Teutônia $\left(27^{\circ} 11^{\prime} \mathrm{S}, 52^{\circ} 23^{\prime} \mathrm{W}, 3-500\right.$ m), 10 Jan-Nov 1961, 1971, F. Plaumann leg. (5 males, 10 females; MZUSP).

Distribution. Nearctic: United States (California). Neotropical: Argentina, Brazil (Santa Catarina), Uruguay.

\section{ACKNOWLEDGMENTS}

We gratefully acknowledge the assistance and cooperation of many organizations and individuals who contributed to the field work and production of this paper. The illustrations were expertly produced by Mirian N. Morales, who is gratefully acknowledged and thanked. The plates were assembled by Michael Biondi and Karolyn Darrow. The latter also expertly photographed and assembled the plate of heads and the hindleg of $P$. arcuata sp. nov. (Figs 7-10) in addition to general enhan- 

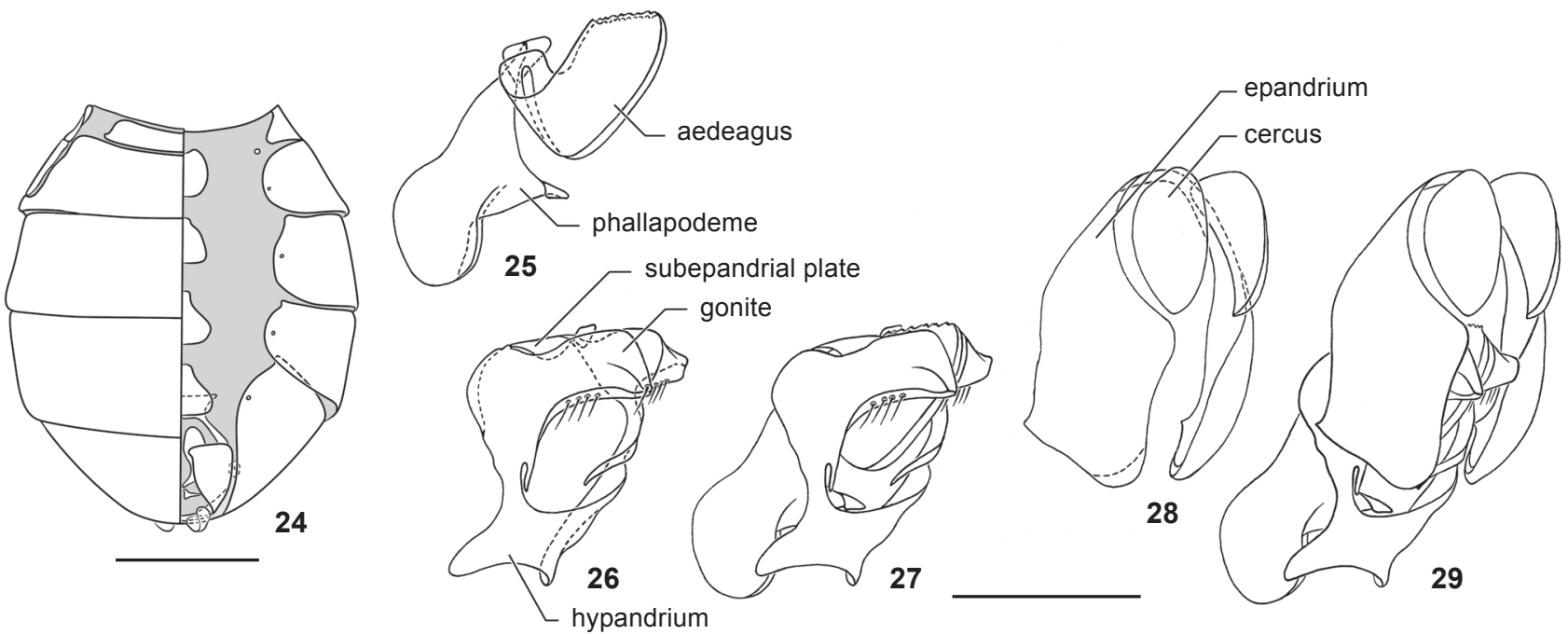

Figures 24-29. Parydra ochropus: (24) abdomen of male, dorsal and ventral views; (25) aedeagus and phallapodeme, latero-oblique view; (26) gonite, hypandrium, and subepandrial plate, latero-oblique view; (27) gonite, hypandrium, subepandrial, and phallapodeme, latero-oblique view; (28) epandrium and cercus, latero-oblique view; (29) male terminalia, latero-oblique view. Scale bars: $24=0.5 \mathrm{~mm}$, $25-29=0.25 \mathrm{~mm}$.

cement of all plates. We also thank Philip J. Clausen for permission to use his previously published illustrations of the other species known from Brazil. For reviewing a draft of this paper we thank two anonymous reviewers. Recent field work in Brazil (December 2009-June 2010) that resulted in the vast majority of specimens studied in this paper was supported by a grant from CNPq (Visiting Researcher/Process 401609/2009-0), which we gratefully acknowledge and thank. We thank Dianne Mathis for helping with all aspects of the production of this paper, especially the field work in Brazil. We also thank A. Bernardo Carvalho and his lab (Elisa, Monica, Susana) for hosting us while conducting field work along the coast of São Paulo. While making visits to museums we were graciously hosted by David A. Grimaldi (AMNH), Jon Gelhaus (ANSP), Márcia S. Couri (MNRJ), and Carlos J.E. Lamas (MZUSP). We express cordial and grateful thanks for their time and many gentilities.

\section{LITERATURE CITED}

Bischof, M.R. \& D.L. Deonier. 1985. Life history and immature stages of Parydra breviceps (Diptera: Ephydridae). Proceedings of the Entomological Society of Washington 87: 805-820.

Clausen, P. J. 1985. A revision of the Neotropical species of the genus Parydra (Diptera: Ephydridae). Transactions of the American Entomological Society 111 (3): 361-384.

Clausen, P.J. \& E.F. Cook. 1971. A revision of the Nearctic species of the tribe Parydrini (Diptera: Ephydridae). Memoirs of the American Entomological Society 27: 1-150.

Coquillett, D.W. 1910. The type-species of the North American genera of Diptera. Proceedings of the United States
National Museum 37: 499-647.

Cresson JR, E.T. 1918. Costa Rican Diptera collected by Philip P. Calvert, Ph.D., 1909-1910. Paper 3. A report on the Ephydridae. Transactions of the American Entomological Society 44: 39-68.

CResson Jr, E.T. 1930. Studies in the dipterous family Ephydridae. Paper III. Transactions of the American Entomological Society 56: 93-131.

Cresson Jr, E. T. 1931. Ephydridae, p. 85-116. In: Diptera of Patagonia and South Chile. 6 (2). British Museum (Natural History), London.

Foote, B.A. 1995. Biology of shore flies. Annual Review of Entomology 40: 417-442.

GrimaLdi, D.A. 1987. Phylogenetics and taxonomy of Zygothrica. Bulletin of the American Museum of Natural History 186: 103-268.

HaLIDAY, A.H. 1855. Recent works on the Diptera of northern Europe. Natural History Review 2: 49-61.

Hendel, F. 1930. Die Ausbeute der deutschen Chaco-Expedition 1925/26. Diptera. XIX. Ephydridae. Konowia 9 (2): 127155.

HÜbner, J. 1819. Verzeichniss bekannter Schmetterlinge. Augsburg, Germany, p. 17-128.

Lioy, P. 1864. I ditteri distribuiti secondo un nuovo metodo di classificazione naturale. Atti dell' I. R. Istituto Veneto di scienze, lettere ed arti series 3, 9: 1087-1126.

Lizarralde de Grosso, M.S. 1989. Ephydridae de la Republica Argentina (Insecta - Diptera). Tucumán, Facultad de Ciencias Naturales, Instituto Miguel Lillo, Universidad Nacional de Tucumán, Serie Monografica y Didactica 3, 93p. 
Mathis, W.N. 1986. Studies of Psilopinae (Diptera: Ephydridae), I: A revision of the shore fly genus Placopsidella Kertész. Smithsonian Contributions to Zoology 430: IV+30p.

Mathis, W.N. \& T. Zatwarnicki. 1990a. A revision of the Western Palearctic species of Athyroglossa (Diptera: Ephydridae). Transactions of the American Entomological Society 116 (1): 103-133.

Mathis, W.N. \& T. Zatwarnicki. 1990b. Taxonomic notes on Ephydridae (Diptera). Proceedings of the Biological Society of Washington 103 (4): 891-906.

Mathis, W.N. \& T. Zatwarnicki. 1995. A world catalog of the shore flies (Diptera: Ephydridae). Memoirs on Entomology International 4: VI+423p.

McAlpine, J.F. 1981. Morphology and Terminology-Adults, p. 9-63. In: J.F. McAlpine; B.V. Peterson; G.E. Shewell; H.J. Teskey; J.R. Vockeroth \& D.M. Wood (Eds). Manual of Nearctic Diptera. Ottawa, vol. 1, 674p.

Robineau-Desvoidy, J.B. 1830. Essai sur les Myodaires. Mémoires Preséntes par divers Savans a l'Académie Royale des Sciences de l'Institut de France, et Imprimés par son Ordre Sciences Mathématiques et Physiques 2 (2): 1-813.

Stenhammar, C. 1844. Försök till Gruppering och Revision af de Svenska Ephydrinae. Kongliga Vetenskaps-Akademiens Handlingar series 3, 1843: 75-272.

Submitted: 20.V.2011; Accepted: 01.VIII.2011.

Editorial responsibility: Gabriel L.F. Mejdalani
Thaxter, R. 1917. New Laboulbeniales, chiefly Dipterophilous American species. Proceedings of the American Academy of Arts and Sciences 52 (10): 647-721.

Thomson, C.G. 1868. 6. Diptera. species nova descripsit, p. 443614, pl. 9 (= h. 12, no. 2). In: Kongliga Svenska VetenskapsAkademien. Kongliga svenska fregaten Eugenies resa omkring jorden [q. v.]. Pt. 2: Zoologie, [Sec.] 1: Insecter, 617 pp. P.A. Norstedt and Söner, Stockholm.

Williston, S.W. 1897. Diptera Brasiliana. Part IV. Kansas University Quarterly series A 6: 1-12.

WIRTH, W.W. 1965. Ephydridae, p. 734-759. In: A. STONE; C.W. Sabrosky; W.W. Wirth; R.H. Foote \& J.R. Coulson (Eds). A Catalog of the Diptera of America North of Mexico. Washington, D.C., U.S. Department of Agriculture, Handbook 276, 1696p.

Wirth, W.W. 1968. 77. Family Ephydridae, p. 1-43. In: N. Papalero (Ed.). A Catalogue of the Diptera of the Americas South of the United States. São Paulo, Departamento de Zoologia, Secretaria da Agricultura.

Wirth, W.W. \& A. Stone. 1956. Aquatic Diptera, p. 372-482. In: R.L. Usinger (Ed.) Aquatic Insects of California. Berkeley, University of California Press, $\mathrm{X}+508 \mathrm{p}$.

ZATWARNICKI, T. 1996. A new reconstruction of the origin of eremoneuran hypopygium and its classification implications (Insecta: Diptera). Genus 7 (1): 103-175. 